\title{
A Cholinergic-Dependent Role for the Entorhinal Cortex in Trace Fear Conditioning
}

\author{
Frederic Esclassan, ${ }^{1,2,3}$ Etienne Coutureau, ${ }^{1,2}$ Georges Di Scala, ${ }^{1,2}$ and Alain R. Marchand ${ }^{1,2}$ \\ ${ }^{1}$ Centre National de la Recherche Scientifique, Centre de Neurosciences Intégratives et Cognitives, Unité Mixte de Recherche (UMR) 5228, and 2Université \\ de Bordeaux, UMR 5228, F-33405 Talence, France, and '3niversité Paul Sabatier, UMR 5169, F-31062 Toulouse, France
}

Trace conditioning is considered a model of higher cognitive involvement in simple associative tasks. Studies of trace conditioning have shown that cortical areas and the hippocampal formation are required to associate events that occur at different times. However, the mechanisms that bridge the trace interval during the acquisition of trace conditioning remain unknown. In four experiments with fear conditioning in rats, we explored the involvement of the entorhinal cortex (EC) in the acquisition of fear under a trace-30 s protocol. We first determined that pretraining neurotoxic lesions of the EC selectively impaired trace-, but not delay-conditioned fear as evaluated by freezing behavior. A local cholinergic deafferentation of the EC using 192-IgG-saporin did not replicate this deficit, presumably because cholinergic interneurons were spared by the toxin. However, pretraining local blockade of EC muscarinic receptors with the M1 antagonist pirenzepine yielded a specific and dose-dependent deficit in trace-conditioned responses. The same microinjections performed after conditioning were without effect on trace fear responses. These effects of blocking M1 receptors are consistent with the notion that conditioned stimulus (CS)-elicited, acetylcholine-dependent persistent activities in the EC are needed to maintain a representation of a tone CS across the trace interval during the acquisition of trace conditioning. This function of the EC is consistent with recent views of this region as a short-term stimulus buffer.

\section{Introduction}

A number of recent studies have shown that higher-level cognitive processes can be addressed through simple associative learning paradigms (Holland, 2008). Particularly challenging is the ability to associate events that are causally related but discontiguous in time (Bangasser et al., 2006). In pavlovian trace conditioning, a conditioned stimulus (CS) is followed with an unconditioned stimulus (US) after a stimulus-free trace interval that can last hundreds of milliseconds in the case of eyeblink conditioning (Gormezano et al., 1983), but tens of seconds in fear conditioning (Marchand and Kamper, 2000). As a result, trace conditioning taps more cognitive resources than standard delay conditioning in which the CS and US are contiguous. It mobilizes attention and awareness (Clark et al., 2002), and requires the participation of specific brain regions such as the prefrontal cortex (Han et al., 2003) and the hippocampal formation (Solomon et al., 1986; McEchron et al., 1998; Yoon and Otto, 2007; Esclassan et al., 2009) in both rodents and humans (Clark and Squire, 1998; Carter et al., 2006).

It has been proposed that the hippocampal formation is required to overcome the temporal discontiguity in trace condi-

\footnotetext{
Received Feb. 2, 2009; revised May 18, 2009; accepted May 19, 2009.

This work was supported by grants from the Centre National de la Recherche Scientifique and Conseil Régional $d^{\prime}$ Aquitaine. F.E. is a fellow of the Ministère de I'Enseignement Supérieur. We are grateful to D. Panzeri, N. Argenta, and J. Huard for animal care, to L. Decorte and A. Faugère for their help in the histological work, and to M. Giurfa for valuable discussions.

Correspondence should be addressed to Dr. Alain R. Marchand, Centre National de la Recherche Scientifique, Centre de Neurosciences Intégratives et Cognitives, UMR 5228, Avenue des Facultés, F-33405 Talence Cedex, France. E-mail: a.marchand@cnic.u-bordeaux1.fr.

DOI:10.1523/JNEUROSCI.0543-09.2009

Copyright $\odot 2009$ Society for Neuroscience $\quad$ 0270-6474/09/298087-07\$15.00/0
}

tioning (Wallenstein et al., 1998; Bangasser et al., 2006). Its function could be to maintain a representation of the CS over time, since fear responses conditioned with trace intervals of long duration (15-30 s) are particularly sensitive to dorsal hippocampal lesions (Chowdhury et al., 2005) or pharmacological manipulations (Misane et al., 2005), whereas conditioning in the absence of trace interval (delay conditioning) or with trace intervals of only a few seconds is generally unaffected (Selden et al., 1991; Phillips and LeDoux, 1992; McEchron et al., 1998; Chowdhury et al., 2005).

The relative participation of the various components of the hippocampal formation to trace conditioning is as yet poorly understood. Processing of trace stimuli could occur upstream of the hippocampus, in the entorhinal cortex (EC) (Ryou et al., 2001). Recent computational theories indeed emphasize the role of the EC as a short-term temporal buffer for novel information (Hasselmo and Stern, 2006). In vitro recordings moreover indicate that neurons from layer $\mathrm{V}$ in the medial EC (Egorov et al., 2002) or layer III in the lateral EC (Tahvildari et al., 2007) show very long persistent responses that are dependent on cholinergic tone, and might encode and maintain information about the CS after its offset. In addition, as a novel stimulus, the CS is expected to elicit cholinergic activity (Acquas et al., 1996). Consequently, acetylcholine-dependent persistent activity in the EC might support the working memory function required to associate events separated in time (McGaughy et al., 2005).

To explore this hypothesis in rats, we first determined that pretraining neurotoxic lesions of the EC selectively impaired trace conditioning. We then evaluated the role of cholinergic afferents using deafferentation by 192-IgG-saporin and local 
pharmacological blockade of M1 muscarinic receptors that are required for persistent activities in the EC. We systematically evaluated the specificity of these effects in trace versus delay procedures.

\section{Materials and Methods}

Subjects and apparatus. Male naive Long-Evans male rats, received at $\sim 8$ weeks of age from the Centre d'Elevage et de Recherche Janvier (le Genest-St-Isle, France), were pair-housed in standard rat cages (polycarbonate, $49 \times 26 \times 20 \mathrm{~cm}$ ) in a temperature-controlled vivarium under a $12 \mathrm{~h}$ light cycle (light on at 7:00 A.M.). All rats were given ad libitum access to food and water. Animal protocols were conducted in agreement with the French (council directive 87848, October 19, 1987; permission 3306793 to A.R.M.) and international (directive 86-609, November 24, 1986, European Community) legislation regarding animal experiments, and care was taken at all stages to minimize stress and discomfort to the animals. Conditioning took place in eight identical conditioning chambers $(40 \times 35 \times 30 \mathrm{~cm}$, Imetronic) made of gray polyvinyl chloride on three sides and transparent Perspex on the opening face. Each chamber was located inside a sound-attenuating cubicle with a loudspeaker above. A grid floor (27 parallel 0.5 -cm-diameter stainless-steel bars, $1.5 \mathrm{~cm}$ apart) above a sawdust tray could deliver mild foot shocks (US, $1 \mathrm{~s}, 0.4$ $\mathrm{mA}$ scrambled pulses). A ventilation fan provided a background noise of $\sim 55 \mathrm{~dB}$. The CS was a tone $(5000 \mathrm{~Hz}, 70 \mathrm{~dB}, 10 \mathrm{~s}$ in duration). Stimuli were delivered by a computerized interface (Imetronic).

Behavioral procedure. The animals, randomly assigned to either a "delay" or a "trace" condition, were submitted to $3 \mathrm{~d}$ of conditioning and testing. During a 30-min-long conditioning session (first day), rats received five tone-shock pairings at pseudo-random intervals. In the delay condition, the onset of the shock coincided with the offset of the tone, whereas the shock was presented after a $30 \mathrm{~s}$ trace interval following the end of the CS in the trace condition. Twenty-four hours later, the rats were again placed in their conditioning chamber for $10 \mathrm{~min}$ to extinguish contextual fear. On the following day, conditioned fear to the tone was evaluated in a 20 min test in an altered context which differed from the original context by visual (black and white visual patterns) and olfactory (removal of the dust tray) features, as well as shape (vertical white separation on the diagonal of the chamber). During this test, after a 5 min stimulus-free period, the animals received three tone presentations with a fixed interval of $5 \mathrm{~min}$. Conditioned fear was assessed using freezing behavior, defined as the absence of all movement. Freezing behavior was quantified using an automatic procedure fully described previously (Marchand et al., 2003; Esclassan et al., 2009). Briefly, images captured by miniature black and white video cameras (SK-2005; OptoVision) monitored rats' movements. An image of the empty cages was subtracted from each sampled frame before computing the SD of pixel values (8-bit). Variation of this SD over three consecutive frames corresponded to a movement of the animal. When movement remained below a fixed threshold (0.075) for at least two consecutive seconds, each second was noted as freezing. Freezing scores were the number of seconds noted as freezing during each period of interest divided by the duration of the same period.

Surgery. Rats submitted to pretraining excitotoxic lesions of the entorhinal cortex were initially anesthetized with a mixture of ketamine (Virbac, $100 \mathrm{mg} / \mathrm{kg}$, i.m.), xylazine (Rompun, $13 \mathrm{mg} / \mathrm{kg}$, i.p.) and diazepam (Valium, $3 \mathrm{mg} / \mathrm{kg}$, i.p.). Using a stereotaxic device (Kopf), excitotoxic lesions of the entorhinal cortex were achieved by injecting NMDA (20 $\mathrm{mg} / \mathrm{ml}$ ) through a glass pipette fitted to a Hamilton syringe, in seven sites on each side, according to the following coordinates (in $\mathrm{mm}$ ): anteroposterior (AP) -6.1 , mediolateral $(\mathrm{ML}) \pm 5.8$, dorsoventral (DV) $-6.9(0.05$ $\mu \mathrm{l})$; $\mathrm{AP}-6.5, \mathrm{ML} \pm 4.7, \mathrm{DV}-7.4(0.025 \mu \mathrm{l}) ; \mathrm{AP}-7, \mathrm{ML} \pm 4.5, \mathrm{DV}-6.6$ $(0.05 \mu \mathrm{l}) ; \mathrm{AP}-7, \mathrm{ML} \pm 5.8, \mathrm{DV}-5.8(0.075 \mu \mathrm{l}) ; \mathrm{AP}-7.5, \mathrm{ML} \pm 4.6, \mathrm{DV}$ $-5.8(0.1 \mu \mathrm{l}) ; \mathrm{AP}-8, \mathrm{ML} \pm 4.7, \mathrm{DV}-5.3(0.1 \mu \mathrm{l})$; $\mathrm{AP}-8.5, \mathrm{ML} \pm 4.8$, DV $-3.6(0.1 \mu \mathrm{l})$. Control rats were submitted to sham lesions, with the cortex being exposed and the dura mater breached in several points.

Pretraining lesions of cholinergic terminals within the entorhinal cortex were performed in rats maintained under anesthesia with isoflurane (1\%). The toxin IgG saporin (Advanced Targeting Systems, $0.4 \mu \mathrm{g} / \mu \mathrm{l}$ ), dissolved in a phosphate buffer vehicle solution, was injected through an elongated glass pipette (tip diameter $30 \mu \mathrm{m}$ ) using a pressure ejection system (Picospritzer II, General Valve Corporation) at the same coordinates as for the excitotoxic lesions (with volumes $0.1,0.05,0.05,0.15,0.2$, 0.2 , and $0.2 \mu \mathrm{l}$, respectively). Rats in the sham group received a similar surgical procedure with injections of vehicle. Injections were made at the rate of $0.1 \mu \mathrm{l} / \mathrm{min}$, and the pipette was left in place for $5 \mathrm{~min}$ after the injection to allow diffusion of the solution into the tissue. IgG saporin infused directly into the cortex binds to the p75 NTR receptor located on cholinergic terminals and is retrogradely transported to the basal forebrain, where it induces a selective loss of cholinergic neurons projecting to the target structure (Ohtake et al., 1997).

Cannulation was performed in ketamine/xylazine-anesthetized rats. Stainless-steel guide cannulae (12 mm long, 36 gauge; American Standard Wire Gauge) were implanted into the entorhinal cortex (AP, -7.5; ML, $\pm 5.5 ; \mathrm{DV},-6.5)$. The guide cannulae were then immobilized in a block of dental cement (PalavitG) that enclosed three small screws fitting into the bone. A stylet inserted into the cannula to prevent clogging was removed before injection. Injection cannulae that extended $1.5 \mathrm{~mm}$ beyond the guide cannulae were used for drug infusions.

After surgery, animals were returned to the vivarium and left to recover for 2 weeks with ad libitum access to food and water.

Pharmacological injections. The M1 receptor antagonist pirenzepine was dissolved in artificial CSF (aCSF) to provide a concentration of 10 $\mathrm{mg} / \mathrm{ml}$ or $15 \mathrm{mg} / \mathrm{ml}$. Then a volume of $0.3 \mu \mathrm{l}$ per side was injected by a motorized infusion pump at a rate of $0.2 \mu \mathrm{l} / \mathrm{min}, 20 \mathrm{~min}$ before the conditioning session in the pretraining experiment or immediately (within $3 \mathrm{~min}$ ) after the conditioning session in the post-training experiment. The test sessions were performed in the absence of drug. Control rats received the same volume of aCSF.

Histology and immunohistochemistry. At the completion of behavioral testing, all animals received a lethal dose of sodium pentobarbital (Ceva Santé Animale). For the histological control of excitotoxic lesions and cannulae placement, rats were perfused transcardially with $60 \mathrm{ml}$ of a $0.9 \%$ sodium chloride solution, followed by $120 \mathrm{ml}$ of a $10 \%$ formaldehyde solution. Brains were stored in a $30 \%$ sucrose-formalin solution for $72 \mathrm{~h}$ before being cut in $50 \mu \mathrm{m}$ sections with a freezing microtome (Leica SM2400). After being collected onto gelatin-coated slides, brain sections were left to dry for $48 \mathrm{~h}$, and finally they were stained with thionin. Section reconstructions were drawn in reference to the atlas of Paxinos and Watson (1998).

To assess the extent of cholinergic denervation, rats were perfused transcardially with $300 \mathrm{ml}$ of $\mathrm{NaCl} 0.9 \%$ solution, followed by $300 \mathrm{ml}$ of paraformaldehyde (PFA) $4 \%$ solution in $0.1 \mathrm{~m}$ phosphate buffer (PB). The brains were removed, postfixed overnight in PFA $4 \%$, and transferred to a PB $0.1 \mathrm{~m} /$ sucrose $30 \%$ solution for $48 \mathrm{~h}$ at $4^{\circ} \mathrm{C}$. Serial coronal sections (50 $\mu \mathrm{m}$ thick) collected and stored in a buffer solution (PB 0.1 $\mathrm{M} /$ azide $0.03 \%$ ) were processed for choline acetyltransferase (ChAT) immunostaining. Free-floating sections were incubated with ChAT primary antibody $(1 / 1000)$ for $24 \mathrm{~h}$ at $4^{\circ} \mathrm{C}$ on a shaker. They were then incubated with biotinylated donkey anti-goat secondary antibody (1/2000 in PB $0.3 \%$, Jackson ImmunoResearch) for $90 \mathrm{~min}$ at room temperature. They were then incubated with avidin-biotin-peroxidase complex (Vector Laboratories) for $90 \mathrm{~min}$ at room temperature. The final staining was made with a diaminobenzidine (Sigma-Aldrich) and hydrogen peroxide solution. Sections were rinsed with Tris buffer, collected on gelatincoated slides, dehydrated with toluene, and mounted in Eukitt mounting medium.

To provide an evaluation of fiber loss, labeled sections were photographed under an Olympus BX50 microscope with a $20 \times$ lens, connected to a Sony DXC-950 camera. Microphotographs of 89 sections of entorhinal cortex (ranging from bregma -6.4 to -7.5 ) were examined. For each section, five circular regions of $200 \mu \mathrm{m}$ diameter per hemisphere were considered. Quantification of ChAT immunoreactivity was performed using an automated method developed in the laboratory using NIH ImageJ software. To determine the number of labeled particles, a black and white digitized version of the microphotograph was smoothed with a Gaussian filter (diameter 12 pixels) and subtracted from the original picture to isolate high spatial frequencies. The picture was 
A

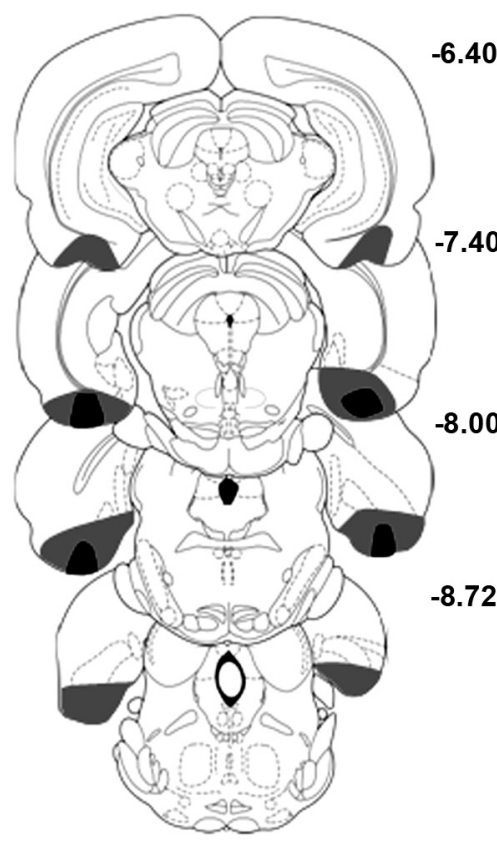

B

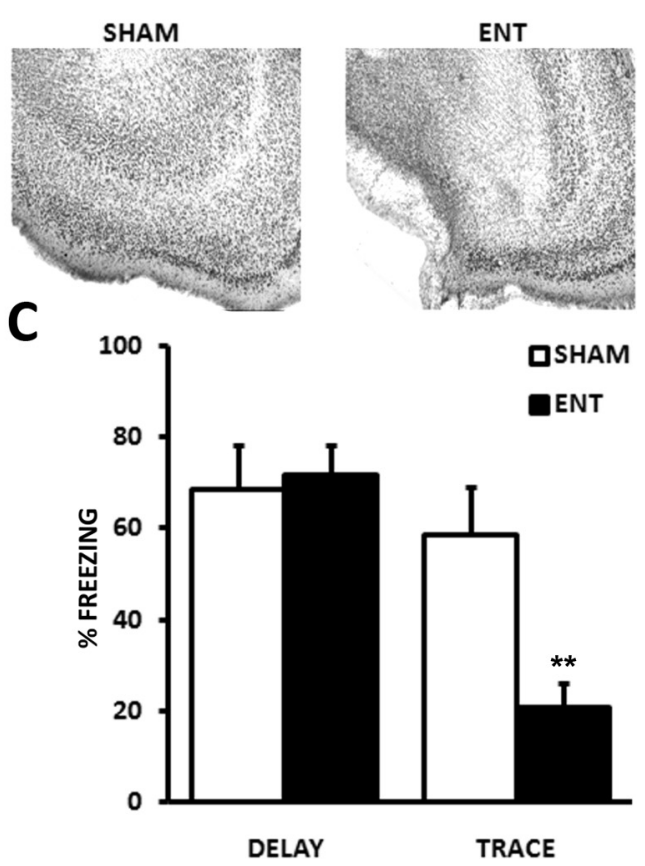

Figure 1. Cell body lesions of the entorhinal cortex impair trace-conditioned fear responses. $\boldsymbol{A}$, Extent of lesions of the entorhinal cortex in the rat sustaining the most extensive (gray) or least extensive (black) lesions. Diagrams adapted from Paxinos and Watson (1998), with distance from bregma in millimeters. $\boldsymbol{B}$, Photomicrographs at bregma $-7.40 \mathrm{~mm}$ of brain sections stained with thionin in a representative lesioned rat (ENT, right) and a control rat (sham, left) show a massive cell loss in both medial and lateral entorhinal cortex. C, Conditioned freezing to the tone in the ENT, trace-conditioned group (right) is markedly reduced with respect to control rats (sham), whereas freezing in the delay-conditioned group (left) is unaffected. ${ }^{* *} p<0.01$.

then subjected to a fixed threshold to identify labeled elements and to a single dilation step to minimize bias by large objects. The number of detected pixels in the circle of interest was then divided by an estimate of the area of each particle (14 pixels) and by the area of the region of interest to yield an estimate of the number and density of particles.

Data analysis. Freezing scores (fraction of time spent freezing) were averaged over specific periods of interest. For the conditioning session, the minute following each of the 5 shocks (postshock freezing) was analyzed in a repeated-measures design. Responses during and after each tone presentation were also examined. For the tone test, freezing responses during the three tone presentations were averaged. These data were analyzed using a two-way ANOVA with condition (delay vs trace) and treatment (lesion or drug) as factors. Partial ANOVAs and StudentNewman-Keuls (SNK) post hoc tests complemented the analysis when appropriate. The $\alpha$ risk was 0.05 throughout.

\section{Results}

\section{Entorhinal involvement in trace conditioning}

To examine the involvement of EC integrity in trace fear conditioning, two groups of rats were conditioned with a trace protocol after EC or sham lesions, T30/entorhinal-lesioned (ENT) $(n=13)$ and T30/sham $(n=9)$, and two other groups were conditioned with a delay protocol, D/ENT $(n=11)$ and D/sham $(n=9)$. Figure $1, A$ and $B$, illustrates the extent of damage to the $\mathrm{EC}$ in the lesioned groups. The cell loss was centered on the medial part of the EC but extended to the lateral EC in most subjects. Freezing during the conditioning session developed normally in all groups [lesion effects; largest $F_{(1,38)}=2.98$, not significant (n.s.) ], with an important carryover of fear from previous shocks. The tone and post-tone responses were thus not informative at this stage of the experiment (supplemental Fig. 1, available at www.jneurosci.org as supplemen- tal material). Figure $1 C$ shows the toneinduced freezing during the final test in all groups. The lesion induced a strong reduction of tone-conditioned freezing in the trace group $\left(F_{(1,20)}=11.98, p<0.01\right)$, but not in the delay group $\left(F_{(1,18)}=0.09\right.$, n.s. $)$, the interaction between lesion and protocol being significant $\left(F_{(1,38)}=6.87, p<0.05\right)$. The cell body lesion of the EC therefore induced a selective deficit in trace-conditioned fear.

\section{Effects of a cholinergic deafferentation} of the entorhinal cortex

To examine the role of cholinergic afferents to the EC during trace conditioning, two groups of rats were submitted to a cholinergic deafferentation of the EC with 192-IgG-saporin (SAP). Two weeks later, they were conditioned with a trace protocol (T30/SAP, $n=10$ ) or a delay protocol (D/SAP, $n=10$ ), and compared with control groups having received an injection of vehicle (T30/PB, $n=9$ and $\mathrm{D} / \mathrm{PB}, n=10)$. Figure $2 \mathrm{~A}$ illustrates the loss of ChAT immunoreactivity produced by the local injection of SAP. As evidenced in Figure $2 B$, the number of detected fibers was reduced on average by $76 \%$ in the EC of SAPtreated animals $\left(F_{(1,33)}=36.6, p<\right.$ $0.0001)$. In contrast, similar numbers of immunostained cell bodies could be observed in lesioned and control rats $\left(F_{(1,33)}\right.$ $=0.32$, n.s.), indicating the presence of cholinergic interneurons that were not affected by the toxin. During the conditioning session, freezing developed normally in all groups (largest $F_{(1,33)}=3.04$, n.s.). As shown in Figure $2 C$, there was no significant effect of the deafferentation on tone-induced freezing (largest $F_{(1,33)}=0.71$, n.s.). Thus, the loss of cholinergic afferents induced by SAP did not affect trace-conditioned fear.

\section{Role of entorhinal M1 receptors in trace conditioning}

The possible contribution of cholinergic mechanisms to the acquisition of trace conditioning was further assessed by blocking postsynaptic muscarinic receptors in the EC. Rats implanted with guide-cannulae in the EC were microinjected with one of two doses of pirenzepine $(10 \mathrm{mg} / \mathrm{ml}$ or $15 \mathrm{mg} / \mathrm{ml}$ ) or vehicle (aCSF) and conditioned with either a trace or a delay protocol, thus yielding six groups: T30/P10 $(n=7), \mathrm{D} / \mathrm{P} 10(n=9), \mathrm{T} 30 / \mathrm{P} 15$ $(n=9), \mathrm{D} / \mathrm{P} 15(n=8), \mathrm{T} 30 / \mathrm{aCSF}(n=8)$, and D/aCSF $(n=8)$. Injection sites are depicted in Figure $3 A$. They were located in the EC in all animals. During the acquisition session, there was no significant effect of injection group on postshock freezing (largest $F_{(2,43)}=0.76$, n.s.), and responses to the tone were not affected by the treatment (supplemental Fig. 2, available at www.jneurosci.org as supplemental material). Figure $3 B$ presents the tone response at test in each of the groups. Rats injected with pirenzepine displayed attenuated trace-conditioned responses. The effects of injection were indeed significant in the trace condition $\left(F_{(2,21)}=4.51, p<0,05\right)$, but not in the delay condition $\left(F_{(2,22)}=\right.$ 0.75 , n.s.), although the interaction between lesion and protocol was not significant $\left(F_{(2,43)}=0.97\right.$, n.s. $)$. The SNK post hoc test indicated that only rats injected with the largest dose showed 
reduced trace-conditioned responses. The blockade of M1 receptors before conditioning thus selectively and dosedependently attenuated trace-conditioned fear, confirming the effects of neurotoxic lesions observed in our first experiment. In addition, two groups of rats conditioned with a trace protocol were microinjected with the higher dose $(15 \mathrm{mg} / \mathrm{ml})$ of pirenzepine or vehicle in the EC immediately after conditioning. No significant effect of these injections on trace-conditioned responses could be detected (aCSF, $52 \pm$ $10 \%$; PIR15, $39 \pm 10 \%$ freezing and SEM, $F_{(1,16)}=0.96$, n.s). These results are consistent with the hypothesis that pirenzepine microinjections suppressed persistent activities required to bridge the trace interval during, but not after, the acquisition phase of trace conditioning.

\section{Discussion}

The present work provides novel indications about the role of the entorhinal cortex in the acquisition of trace conditioning. We show that conditioned fear responses to a tone are disrupted by pretraining cell body lesions of the entorhinal cortex under a trace protocol, but not under a delay protocol. Local injections of the toxin 192-IgGsaporin strongly reduced the number of cholinergic terminals in the EC but failed to affect conditioned responses. Nevertheless, microinjections of the M1 muscarinic receptor antagonist pirenzepine within the EC replicated the effects of lesions when performed before but not after conditioning.

Our study was focused on the acquisition phase of trace conditioning. During the conditioning session itself, the freezing response during and after the CS largely reflected residual fear from the previous shock, so that no group differences emerged in any of the experiments. Differences in learning were thus only evident during subsequent tests. The effects of pretraining neurotoxic lesions of the EC on trace fear conditioning extend the findings of Ryou et al. (2001), obtained in the conditioned eyeblink preparation, and furthermore show that this deficit is selective to trace conditioning, sparing delay conditioning. We recently showed that the dorsal part of the hippocampus is specifically required to establish trace fear conditioning, whereas the ventral part also contributed, but in a less specific manner (Esclassan et al., 2009). It is, however, unlikely that the EC serves as a simple relay for the transmission of information from the sensory thalamus and parahippocampal cortices to the hippocampus (Kerr et al., 2007). Indeed, an increasing number of studies indicate distinct roles of the EC and of the hippocampus proper in information processing (Coutureau et al., 1999, 2002; Shohamy et al., 2000; Talnov et al., 2003; Sargolini et al., 2006). Moreover, no persistent activity bridging the long time gap between the CS and US has so far been recorded in the hippocampus proper during trace fear conditioning (Gilmartin and McEchron, 2005). Processing could take place in the EC and the information could be relayed not only to the hippocampus, but also directly to subcortical structures involved in fear conditioning, such as the amygdalar complex (Pitkanen et al., 2000) or the nucleus accumbens (Totterdell and Meredith,
PB

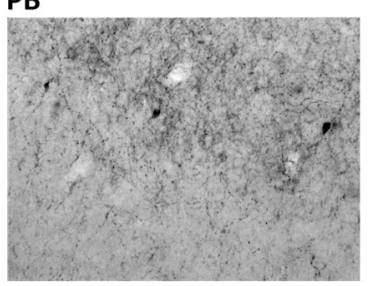

Cell bodies

ibers

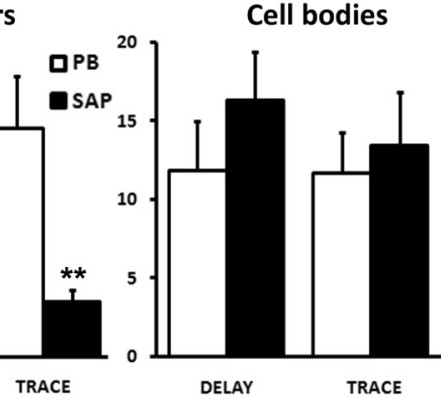

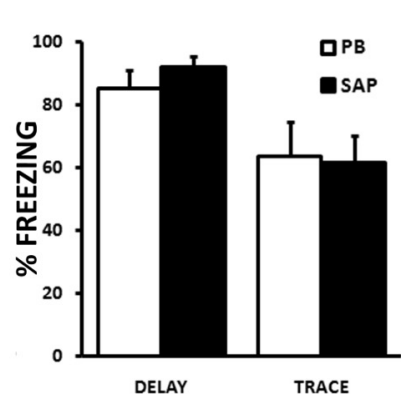

SAP

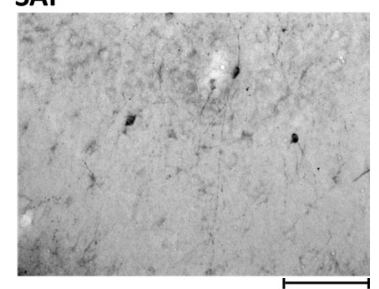

C
1997). This might allow the EC to substitute for the auditory cortex in the classical circuit (LeDoux, 2000) of fear conditioning.

Our data highlight the contribution of cholinergic innervation within the EC to trace conditioning. The local injections of the toxin 192-IgG-saporin directly into the EC used here produced an anatomically selective and drastic decrease in the number of immunoreactive fibers within the EC. This denervation was without effect, in contrast with a previous report of an impairment of trace conditioning after neurotoxic lesions of the medial septum/diagonal band (McAlonan et al., 1995). However, the latter lesions were less selective, eliminating not only cholinergic projections to the hippocampus and entorhinal cortex, but also to the anterior cingulate cortex (Gaykema et al., 1990), which appears involved in trace conditioning (Han et al., 2003). However, deficits in a working memory task requiring the maintenance of novel olfactory information can be induced by the injection of a large volume of SAP into the EC (McGaughy et al., 2005). We observed residual cholinergic fibers in the EC of deafferented rats, as well as similar numbers of immunoreactive cell bodies as in control rats, corresponding to bipolar cholinergic interneurons that are known to provide an important source ( $\sim 30 \%$ ) of cholinergic innervation in the cortex (Bayraktar et al., 1997). These neurons appear insensitive to the toxin, presumably because they do not express the p75 NTR receptor (de Lacalle et al., 1998), and they should thus prevent a complete denervation by 192-IgG-saporin. Residual levels of acetylcholine may be sufficient for the present task, as observed in other preparations (Gutiérrez et al., 1999; Chudasama et al., 2004; Marques Pereira et al., 2005). A fraction of cortical cholinergic interneurons that express vasoactive intestinal polypeptide has been suggested to participate in local cerebrovascular regulation (Chédotal et al., 1994), but their functional role, in general, and in the EC, in particular, is largely unknown (Bayraktar et al., 1997) and may have been underestimated. Alternatively, we cannot exclude that 

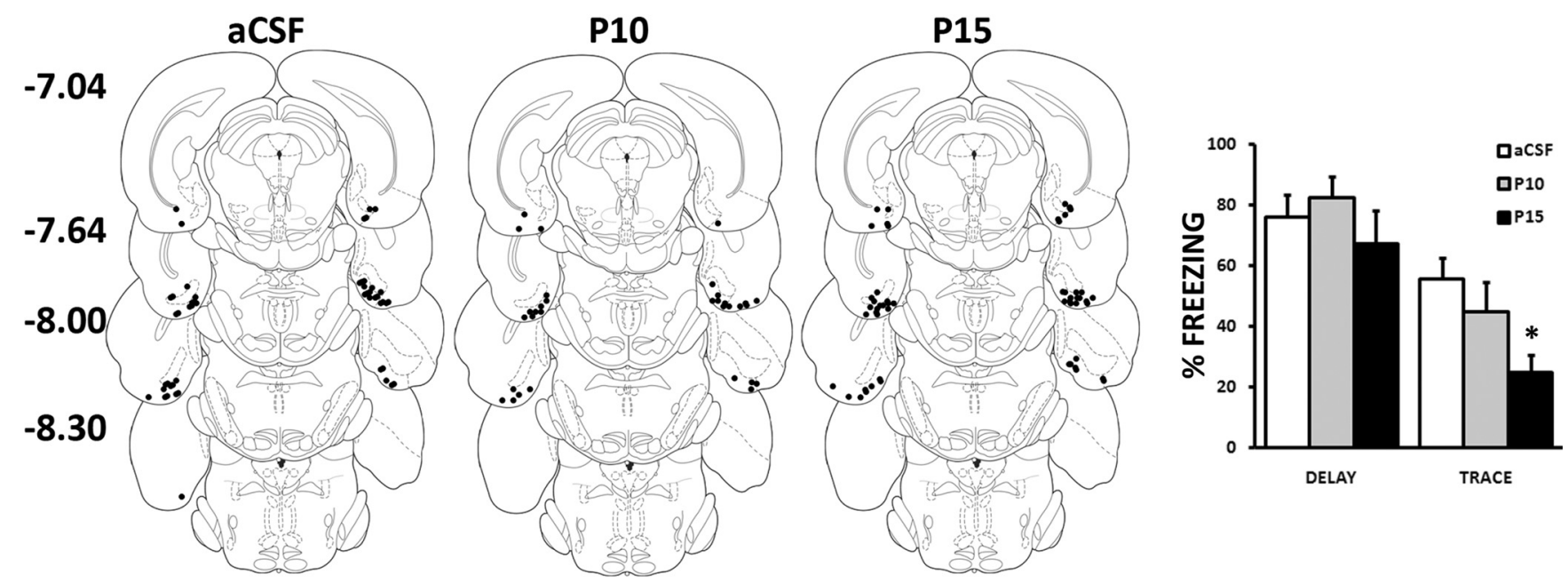

Figure 3. Effects of pirenzepine microinjections in the entorhinal cortex. A, Location of the injection sites in the entorhinal cortex of rats injected bilaterally with $0.3 \mu$ l of aCSF or two doses of pirenzepine (P10, $10 \mathrm{mg} / \mathrm{ml} ;$ P15, $15 \mathrm{mg} / \mathrm{ml})$. Diagrams adapted from Paxinos and Watson (1998), with distance from bregma in millimeters. $\boldsymbol{B}$, Conditioned freezing to the tone in the trace-conditioned group injected with pirenzepine before conditioning is markedly reduced with respect to rats injected with vehicle (right), whereas freezing in the delay-conditioned group (left) is unaffected. ${ }^{*} p<0.05$.

the cholinergic deafferentation may have induced compensatory changes in the expression of metabotropic glutamate receptors, resulting in facilitation or restoration of persistent firing in entorhinal cortex neurons (Yoshida et al., 2008).

Our results clearly indicate that cholinergic activity within the $\mathrm{EC}$ is required for trace conditioning, since pirenzepine injected directly into the EC was sufficient to greatly impair trace fear responses. Most of the effects of the antagonist appear to be restricted to the acquisition phase, since pirenzepine had no significant effect when injected just after the conditioning session. This indicates that putative effects of pirenzepine on consolidation processes are less important than effects in acquisition, in agreement with our hypothesis. Moreover, these effects are selective for trace conditioning, since rats conditioned under a delay protocol were not impaired. Pirenzepine may affect neuronal responses up to $5 \mathrm{~h}$ after injection, but not after $24 \mathrm{~h}$ (Bocian and Konopacki, 2004), so that the drug was absent during the tone test conducted $48 \mathrm{~h}$ after injection in both the pretraining and post-training injection experiments. Our data nevertheless do not exclude the possibility that the EC may also contribute to the expression of trace-, but not of delay-conditioned responses. This issue would require further studies, since inactivating the $\mathrm{EC}$ at test in aversive tasks does not appear to produce consistent effects (Izquierdo et al., 1997; Baldi et al., 1998; Lewis and Gould, 2007).

Data about the role of cholinergic modulation of the EC in tasks requiring the short-term maintenance of information are still scarce (Tang et al., 1997; McGaughy et al., 2005). Nevertheless, systemic injections of muscarinic antagonists have been shown to impair trace conditioning (Kaneko and Thompson, 1997; Seager et al., 1999; Hunt et al., 2006), and the EC could be a site of action for these drugs.

The effects of pirenzepine in vivo indicate that trace conditioning and the persisting activities that have been described in vitro (Egorov et al., 2002) both depend on the activation of M1 receptors within the EC. The M1 receptor is largely represented on cortical and striatal cell bodies and neurites, consistent with its role as a major postsynaptic muscarinic receptor (Levey et al., 1991). Blocking M1 receptors in the EC with pirenzepine may thus prevent both septohippocampal cholinergic activation and the effects of residual acetylcholine released by interneurons.

Persistent activities in the EC could contribute to trace conditioning in the following way. A natural stimulus, such as the tone used as a CS, may depolarize entorhinal neurons (Vinogradova, 2001), as well as activate septohippocampal cholinergic projections (Acquas et al., 1996), thereby triggering persistent activities. Intrinsic membrane properties in the $\mathrm{EC}$ are sufficient to maintain a trace of novel stimuli without the need for synaptic plasticity (Hasselmo and Stern, 2006). The activities constituting the trace could thus become associated with the US at the end of the trace interval by simple contiguity. Further experiments would be needed to confirm the role and duration of persistent activities in vivo.

We did not present here the freezing response after CS offset since, as previously reported (Esclassan et al., 2009), it essentially follows the pattern observed during the CS itself. Interestingly, this absence of temporal specificity with long trace intervals (Marchand and Kamper, 2000; Quinn et al., 2002; Marchand et al., 2003) may be attributable to the fact that temporally stable persistent discharges do not bear information about elapsed time. This contrasts with trace eyeblink conditioning, for which hippocampal-dependent, temporally selective mechanisms have been proposed (Grossberg and Merrill, 1992; Levy et al., 2005; Hasselmo et al., 2007). Nevertheless, acetylcholine is rapidly degraded by hydrolysis in the cortex (Bruno et al., 2006), which may limit the range of acceptable trace intervals. This would be consistent with the facilitation of trace conditioning by cholinesterase inhibitors that has been observed in young rats (Hunt and Richardson, 2007). In addition, long trace intervals should increase the likelihood of distractors resetting neuronal activity, thereby preventing conditioning (Han et al., 2003).

To date, the involvement of the entorhinal cortex in trace fear conditioning had not been previously reported. The requirement for the EC in the absence of temporal contiguity (Chowdhury et al., 2005; Bangasser et al., 2006) is consistent with a role of this structure as a short-term temporal buffer (Hasselmo and Stern, 2006). According to this notion, successive stimuli occurring in 
the environment would be gradually incorporated into the pattern of EC neuronal activity, the trace of the older stimuli decaying as new events appear. Finally, cortical processing of the CS within the entorhinal cortex might explain why trace conditioning requires conscious awareness of the relationship between the CS and US events (Clark and Squire, 1998; Carter et al., 2003).

\section{References}

Acquas E, Wilson C, Fibiger HC (1996) Conditioned and unconditioned stimuli increase frontal cortical and hippocampal acetylcholine release: effects of novelty, habituation, and fear. J Neurosci 16:3089-3096.

Baldi E, Ambrogi Lorenzini C, Sacchetti B, Tassoni G, Bucherelli C (1998) Entorhinal cortex and fimbria-fornix role in rat's passive avoidance response memorization. Brain Res 799:270-277.

Bangasser DA, Waxler DE, Santollo J, Shors TJ (2006) Trace conditioning and the hippocampus: the importance of contiguity. J Neurosci 26:8702-8706.

Bayraktar T, Staiger JF, Acsady L, Cozzari C, Freund TF, Zilles K (1997) Co-localization of vasoactive intestinal polypeptide, gammaaminobutyric acid and choline acetyltransferase in neocortical interneurons of the adult rat. Brain Res 757:209-217.

Bocian R, Konopacki J (2004) The effect of posterior hypothalamic injection of cholinergic agents on hippocampal formation theta in freely moving cat. Brain Res Bull 63:283-294.

Bruno JP, Gash C, Martin B, Zmarowski A, Pomerleau F, Burmeister J, Huettl P, Gerhardt GA (2006) Second-by-second measurement of acetylcholine release in prefrontal cortex. Eur J Neurosci 24:2749-2757.

Carter RM, Hofstotter C, Tsuchiya N, Koch C (2003) Working memory and fear conditioning. Proc Natl Acad Sci U S A 100:1399-1404.

Carter RM, O’Doherty JP, Seymour B, Koch C, Dolan RJ (2006) Contingency awareness in human aversive conditioning involves the middle frontal gyrus. Neuroimage 29:1007-1012.

Chédotal A, Cozzari C, Faure MP, Hartman BK, Hamel E (1994) Distinct choline acetyltransferase (ChAT) and vasoactive intestinal polypeptide (VIP) bipolar neurons project to local blood vessels in the rat cerebral cortex. Brain Res 646:181-193.

Chowdhury N, Quinn JJ, Fanselow MS (2005) Dorsal hippocampus involvement in trace fear conditioning with long, but not short, trace intervals in mice. Behav Neurosci 119:1396-1402.

Chudasama Y, Dalley JW, Nathwani F, Bouger P, Robbins TW (2004) Cholinergic modulation of visual attention and working memory: dissociable effects of basal forebrain 192-IgG-saporin lesions and intraprefrontal infusions of scopolamine. Learn Mem 11:78-86.

Clark RE, Squire LR (1998) Classical conditioning and brain systems: the role of awareness. Science 280:77-81.

Clark RE, Manns JR, Squire LR (2002) Classical conditioning, awareness, and brain systems. Trends Cogn Sci 6:524-531.

Coutureau E, Galani R, Gosselin O, Majchrzak M, Di Scala G (1999) Entorhinal but not hippocampal or subicular lesions disrupt latent inhibition in rats. Neurobiol Learn Mem 72:143-157.

Coutureau E, Killcross AS, Good M, Marshall VJ, Ward-Robinson J, Honey RC (2002) Acquired equivalence and distinctiveness of cues: II. Neural manipulations and their implications. J Exp Psychol Anim Behav Process 28:388-396.

de Lacalle S, Kulkarni S, Wiley RG (1998) Lesion-induced transneuronal plasticity of the cholinergic innervation in the adult rat entorhinal cortex. Eur J Neurosci 10:1054-1062.

Egorov AV, Hamam BN, Fransén E, Hasselmo ME, Alonso AA (2002) Graded persistent activity in entorhinal cortex neurons. Nature 420:173-178

Esclassan F, Coutureau E, Di Scala G, Marchand AR (2009) Differential contribution of dorsal and ventral hippocampus to trace and delay fear conditioning. Hippocampus 19:33-44.

Gaykema RP, Luiten PG, Nyakas C, Traber J (1990) Cortical projection patterns of the medial septum-diagonal band complex. J Comp Neurol 293:103-124.

Gilmartin MR, McEchron MD (2005) Single neurons in the dentate gyrus and CA1 of the hippocampus exhibit inverse patterns of encoding during trace fear conditioning. Behav Neurosci 119:164-179.

Gormezano I, Kehoe EJ, Marshall BS (1983) Twenty years of classical conditioning research with the rabbit. Prog Psychobiol Physiol Psychol 10:197-275.
Grossberg S, Merrill JW (1992) A neural network model of adaptively timed reinforcement learning and hippocampal dynamics. Brain Res Cogn Brain Res 1:3-38.

Gutiérrez H, Gutiérrez R, Silva-Gandarias R, Estrada J, Miranda MI, Bermúdez-Rattoni F (1999) Differential effects of 192IgG-saporin and NMDA-induced lesions into the basal forebrain on cholinergic activity and taste aversion memory formation. Brain Res 834:136-141.

Han CJ, O’Tuathaigh CM, van Trigt L, Quinn JJ, Fanselow MS, Mongeau R, Koch C, Anderson DJ (2003) Trace but not delay fear conditioning requires attention and the anterior cingulate cortex. Proc Natl Acad Sci U S A 100:13087-13092.

Hasselmo ME, Stern CE (2006) Mechanisms underlying working memory for novel information. Trends Cogn Sci 10:487-493.

Hasselmo ME, Giocomo LM, Zilli EA (2007) Grid cell firing may arise from interference of theta frequency membrane potential oscillations in single neurons. Hippocampus 17:1252-1271.

Holland PC (2008) Cognitive versus stimulus-response theories of learning. Learn Behav 36:227-241.

Hunt PS, Richardson R (2007) Pharmacological dissociation of trace and long-delay fear conditioning in young rats. Neurobiol Learn Mem 87:86-92.

Hunt PS, Barnet RC, Shea ME, Baker EM (2006) Cholinergic modulation of trace conditioning trained in serial compound: a developmental analysis. Neurobiol Learn Mem 86:311-321.

Izquierdo I, Quillfeldt JA, Zanatta MS, Quevedo J, Schaeffer E, Schmitz PK, Medina JH (1997) Sequential role of hippocampus and amygdala, entorhinal cortex and parietal cortex in formation and retrieval of memory for inhibitory avoidance in rats. Eur J Neurosci 9:786-793.

Kaneko T, Thompson RF (1997) Disruption of trace conditioning of the nictitating membrane response in rabbits by central cholinergic blockade. Psychopharmacology (Berl) 131:161-166.

Kerr KM, Agster KL, Furtak SC, Burwell RD (2007) Functional neuroanatomy of the parahippocampal region: the lateral and medial entorhinal areas. Hippocampus 17:697-708.

LeDoux JE (2000) Emotion circuits in the brain. Annu Rev Neurosci 23:155-184.

Levey AI, Kitt CA, Simonds WF, Price DL, Brann MR (1991) Identification and localization of muscarinic acetylcholine receptor proteins in brain with subtype-specific antibodies. J Neurosci 11:3218-3226.

Levy WB, Sanyal A, Rodriguez P, Sullivan DW, Wu XB (2005) The formation of neural codes in the hippocampus: trace conditioning as a prototypical paradigm for studying the random recoding hypothesis. Biol Cybern 92:409-426.

Lewis MC, Gould TJ (2007) Reversible inactivation of the entorhinal cortex disrupts the establishment and expression of latent inhibition of cued fear conditioning in C57BL/6 mice. Hippocampus 17:462-470.

Marchand AR, Kamper E (2000) Time course of cardiac conditioned responses in restrained rats as a function of the trace CS-US interval. J Exp Psychol Anim Behav Process 26:385-398.

Marchand AR, Luck D, DiScala G (2003) Evaluation of an improved automated analysis of freezing behaviour in rats and its use in trace fear conditioning. J Neurosci Methods 126:145-153.

Marques Pereira P, Cosquer B, Schimchowitsch S, Cassel JC (2005) HebbWilliams performance and scopolamine challenge in rats with partial immunotoxic hippocampal cholinergic deafferentation. Brain Res Bull 64:381-394.

McAlonan GM, Wilkinson LS, Robbins TW, Everitt BJ (1995) The effects of AMPA-induced lesions of the septo-hippocampal cholinergic projection on aversive conditioning to explicit and contextual cues and spatial learning in the water maze. Eur J Neurosci 7:281-292.

McEchron MD, Bouwmeester H, Tseng W, Weiss C, Disterhoft JF (1998) Hippocampectomy disrupts auditory trace fear conditioning and contextual fear conditioning in the rat. Hippocampus 8:638-646.

McGaughy J, Koene RA, Eichenbaum H, Hasselmo ME (2005) Cholinergic deafferentation of the entorhinal cortex in rats impairs encoding of novel but not familiar stimuli in a delayed nonmatch-to-sample task. J Neurosci 25:10273-10281.

Misane I, Tovote P, Meyer M, Spiess J, Ogren SO, Stiedl O (2005) Timedependent involvement of the dorsal hippocampus in trace fear conditioning in mice. Hippocampus 15:418-426.

Ohtake T, Heckers S, Wiley RG, Lappi DA, Mesulam MM, Geula C (1997) Retrograde degeneration and colchicine protection of basal forebrain 
cholinergic neurons following hippocampal injections of an immunotoxin against the P75 nerve growth factor receptor. Neuroscience 78:123-133.

Paxinos G, Watson C (1998) The rat brain in stereotaxic coordinates, Ed 4. New York: Academic.

Phillips RG, LeDoux JE (1992) Differential contribution of amygdala and hippocampus to cued and contextual fear conditioning. Behav Neurosci 106:274-285.

Pitkanen A, Pikkarainen M, Nurminen N, Ylinen A (2000) Reciprocal connections between the amygdala and the hippocampal formation, perirhinal cortex, and postrhinal cortex in rat. A review. Ann N Y Acad Sci 911:369-391.

Quinn JJ, Oommen SS, Morrison GE, Fanselow MS (2002) Post-training excitotoxic lesions of the dorsal hippocampus attenuate forward trace, backward trace, and delay fear conditioning in a temporally specific manner. Hippocampus 12:495-504.

Ryou JW, Cho SY, Kim HT (2001) Lesions of the entorhinal cortex impair acquisition of hippocampal-dependent trace conditioning. Neurobiol Learn Mem 75:121-127.

Sargolini F, Fyhn M, Hafting T, McNaughton BL, Witter MP, Moser MB, Moser EI (2006) Conjunctive representation of position, direction, and velocity in entorhinal cortex. Science 312:758-762.

Seager MA, Asaka Y, Berry SD (1999) Scopolamine disruption of behavioral and hippocampal responses in appetitive trace classical conditioning. Behav Brain Res 100:143-151.

Selden NR, Everitt BJ, Jarrard LE, Robbins TW (1991) Complementary roles for the amygdala and hippocampus in aversive conditioning to explicit and contextual cues. Neuroscience 42:335-350.
Shohamy D, Allen MT, Gluck MA (2000) Dissociating entorhinal and hippocampal involvement in latent inhibition. Behav Neurosci 114:867-874

Solomon PR, Vander Schaaf ER, Thompson RF, Weisz DJ (1986) Hippocampus and trace conditioning of the rabbit's classically conditioned nictitating membrane response. Behav Neurosci 100:729-744.

Tahvildari B, Fransén E, Alonso AA, Hasselmo ME (2007) Switching between "On" and "Off" states of persistent activity in lateral entorhinal layer III neurons. Hippocampus 17:257-263.

Talnov AN, Quian Quiroga R, Meier M, Matsumoto G, Brankack J (2003) Entorhinal inputs to dentate gyrus are activated mainly by conditioned events with long time intervals. Hippocampus 13:755-765.

Tang Y, Mishkin M, Aigner TG (1997) Effects of muscarinic blockade in perirhinal cortex during visual recognition. Proc Natl Acad Sci U S A 94:12667-12669.

Totterdell S, Meredith GE (1997) Topographical organization of projections from the entorhinal cortex to the striatum of the rat. Neurosci 78:715-729.

Vinogradova OS (2001) Hippocampus as comparator: role of the two input and two output systems of the hippocampus in selection and registration of information. Hippocampus 11:578-598.

Wallenstein GV, Eichenbaum H, Hasselmo ME (1998) The hippocampus as an associator of discontiguous events. Trends Neurosci 21:317-323.

Yoon T, Otto T (2007) Differential contributions of dorsal vs. ventral hippocampus to auditory trace fear conditioning. Neurobiol Learn Mem $87: 464-475$.

Yoshida M, Fransén E, Hasselmo ME (2008) mGluR-dependent persistent firing in entorhinal cortex layer III neurons. Eur J Neurosci 28:11161126. 